\title{
Green versus Gray: Attitudes toward Vegetation in a Tropical Metropolitan Square
}

\author{
Luis Santiago ${ }^{1}$, Tatiana Gladkikh ${ }^{1}$, Liz Betancourt ${ }^{1} \&$ Yaheli Vargas ${ }^{1}$ \\ ${ }^{1}$ Graduate School of Planning, University of Puerto Rico, San Juan, Puerto Rico \\ Correspondence: Luis Santiago, Graduate School of Planning, University of Puerto Rico, PO Box 23354, San \\ Juan Puerto Rico 00931-3354. Tel: 787-764-0000 ext 85113. E-mail:luis.santiago47@upr.edu
}

\author{
Received: March 23, 2015 Accepted: April 11, 2015 Online Published: April 20, 2015 \\ doi:10.5539/enrr.v5n2p109 URL: http://dx.doi.org/10.5539/enrr.v5n2p109
}

\begin{abstract}
Urban squares play an increasingly important role as spaces with green areas where residents can connect with nature and consume ecological amenities. Our research investigated user attitudes and preferences towards the presence, use and benefits of green infrastructure in Convalecencia Square, a main city square in San Juan, Puerto Rico with an unusual dual configuration and regulatory structure. Users were interviewed to assess preferences and attitudes towards vegetation and uses. A tripartite model that considered cognitive, affective and behavioral components was used to examine attitudes towards green areas, and choice experiment based methodology facilitated assessment of user preferences towards existing and hypothetical gray/green infrastructure configurations. Findings show that, with the exception of those expressing visions akin to those of the hygienic city imaginary, users show strong affective outlooks towards green infrastructure, placing emphasis on aesthetic components, and exhibiting a limited identification of cognitive components such as the role of ecosystem services. Education on green area ecosystem services could help bridge the gap between affective and cognitive components. Furthermore, gender differences on green infrastructure configuration choices point to the idea of exploring gender-differentiated green area conservation and development strategies.
\end{abstract}

Keywords: ecosystem services, green areas, green infrastructure, urban vegetation

\section{Introduction}

Urban squares play an increasingly important role as spaces with green areas where residents can connect with nature and consume ecological amenities (Baur, Tynon, \& Gomez, 2013; Santiago, Verdejo-Ortiz, Santiago-Bartolomei, Meléndez, \& García-Montiel, 2014; Wright Wendel, Zarger, \& Mihelcic, 2012). Facing shrinking budgets and urban development pressures, government officials may find justifying maintenance and expansion of urban green infrastructure an increasingly difficult task. Quality of life in cities depends on ecosystem services generated locally within cities (Andersson, Tengo, McPhearson, \& Kremer, in press). The value of ecosystem services provided by urban green areas, however, is consistently unaccounted or undervalued in government decision-making. The ecosystem services framework, validated by the Millennium Ecosystem Assessment (MEA, 2005) allows for proper accounting and valuation of provision, regulating, and cultural services derived from green infrastructure.

The proposed research investigates user attitudes and preferences towards the presence, use and benefits of green infrastructure in Convalecencia Square, one of the main city squares in San Juan, Puerto Rico, using innovative Choice Experiment based methodology and an ecosystem services framework. Figure 1 shows the square's location within the Municipality of San Juan (right hand side), Puerto Rico's capital, and in its regional Caribbean context (upper left-hand side). This square is of particular interest due to a dual configuration and regulatory structure. In 2010, the municipality of San Juan rebuilt a section of the square with new gray and green infrastructure while implementing in it more restrictive use regulations, such as forbidding the use of skateboards.

The Convalecencia Square is located in Rio Piedras, a ward of San Juan, the capital of Puerto Rico. During Spanish colonial times, a town hall and a Catholic Church were traditionally built around town squares, and the Convalecencia was no exception. The church was founded long before the square, in 1714, but hurricanes passing through the island deteriorated the church structure, and the structure was rebuilt in the $19^{\text {th }}$ century. 

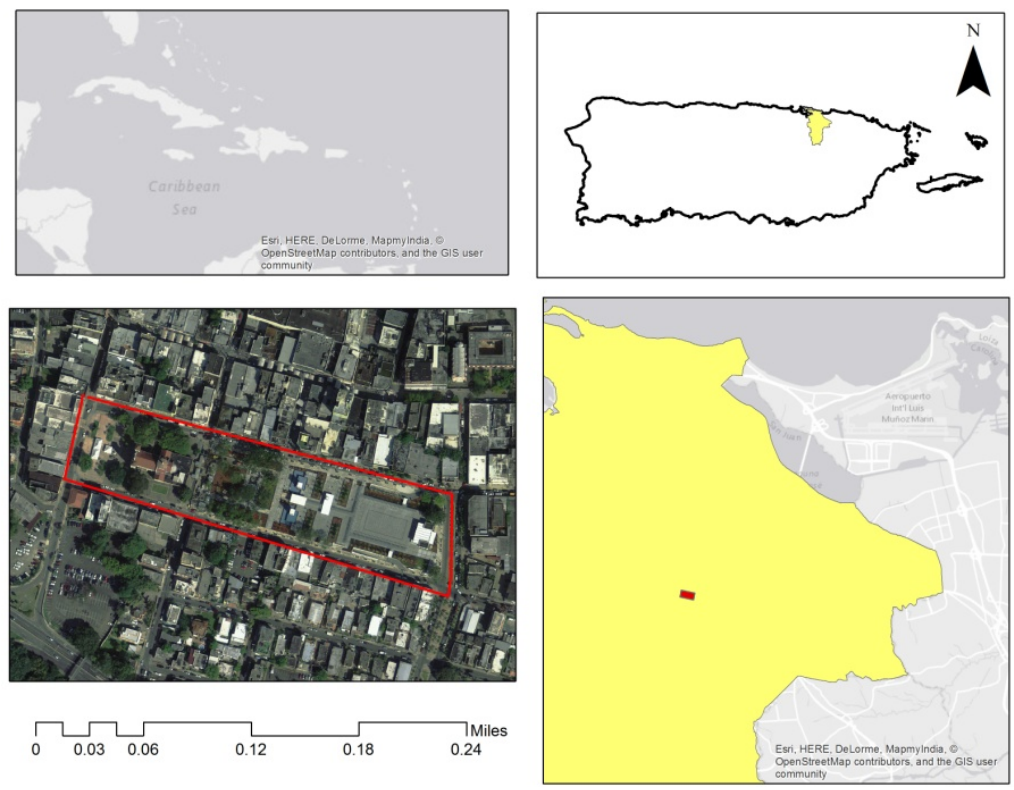

Figure 1. Convalecencia Square in its Regional Context

The square was also the location of the governor's recreation home in the $19^{\text {th }}$ century, which later became a convalescent home for Spanish Troops. During the late nineteenth century the square became a passive recreation square. Due to its location, Rio Piedras became a transportation hub that connected San Juan with the rest of the island. As early as 1835 there was a public transportation platform that provided service between Rio Piedras and the San Juan core.

In 1903, the University of Puerto Rico was founded in Rio Piedras. University employees and students added to increasing development pressures in San Juan, propitiating urban growth in the area. Several residential neighborhoods were built between 1930 and 1952. Rio Piedras officially became a ward of the Municipality of San Juan on July $1^{\text {st }}, 1951$.

In the 1950's, the Convalecencia Square was transformed with the construction of facilities for open-air concerts, electric lighting, gardens with a water irrigation system, sidewalks, and benches. An underground parking was later built to accommodate the increasing passenger traffic in the area and was also thought as an underground shelter in case of a nuclear war.

Another characteristic that makes this town square particularly noteworthy is its function as a public transport hub. There are three different means of public transport which can be directly accessed from the square: a San Juan metro stop, a public bus stop, and a center for private mini-buses serving other regions of the San Juan metropolitan area.

The former mayor of San Juan presented in 2008 a new vision for the urban core of Rio Piedras, called Rio 2012. The new vision proposed, during its first phase, a major renovation of the town square. In 2010, the renovations in the east side of the town square were completed (see Figure 2). There are now five fountains in that area, 57 lighting posts, 3 trash cans, access ramps, 12 parking spaces, 3 security cameras, security personnel, and a variety of planted vegetation, more colorful than the one at the west side.

The town square is of particular interest because only the east side of the square was rebuilt, while the west side was not. The older section has a public bus stop with a bench, 3 garbage cans, 2 public telephones, 27 lighting posts, a US Post Office Mailbox, a vegetable garden, and a Catholic Church. Due to their longevity, there are more lush or leafy trees in this side. Visitors sit by the edge of the planting areas where trees and other vegetation are located. The border is not as wide as in the rebuilt section of the square, making it a bit more uncomfortable to sit in this area. The west side of the square has a more traditional character, since it has remained largely unchanged for more than half a century. Such marked physical differences in the square make it an interesting laboratory to measure visitor preferences in vegetation and facilities. 


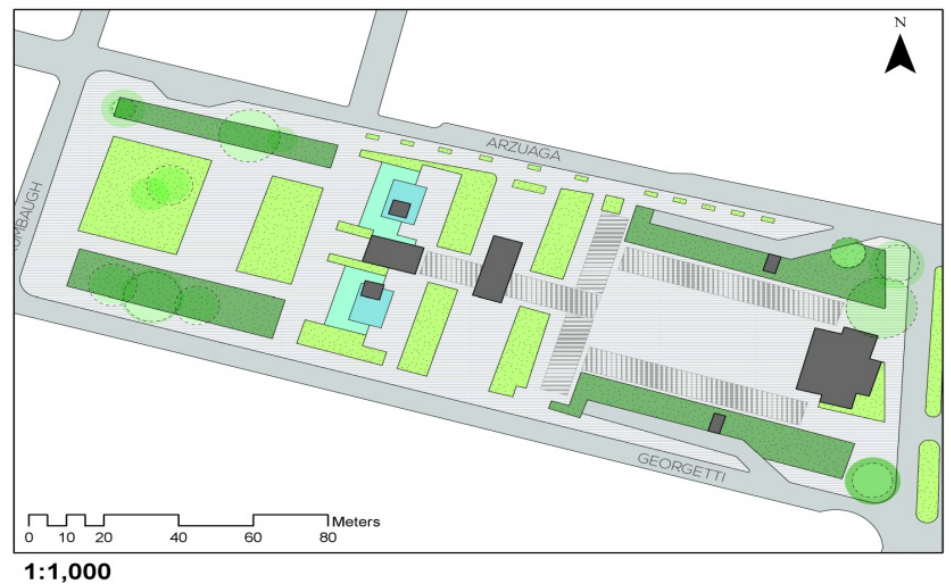

Figure 2. Convalecencia Square: Current view

\section{Literature Review}

Originally, merely a decorative element in towns and cities, green space has now taken on a new value and function, the importance of which is widely acclaimed within the parameters of sustainable development (Sanesi \& Chiarello, 2006; Jim, 2008). Green areas are known to provide physical, social and psychological benefits, as well as ecosystem services (Baur et al., 2013; Nordh \& Otsby, 2013). Cultural services provided by green space networks and in particular leisure and recreational opportunities are central to the quality of life of those living in urban areas (Besser, McLain, Cerveny, Biedenweg, \& Banis, 2014). Shielded from disturbing surroundings and furnished with some seating, they promote opportunities for restorative experiences and function as social meeting places (Nordh \& Otsby, 2013).

Recreation area professionals need to understand public attitudes about urban nature spaces so management can be responsive to public needs (Baur et al., 2013). Attitudes influence behavior towards urban green spaces, but determining attitudes toward urban green spaces is not well operationalized in urban planning research (Balram \& Dragićević, 2005).

Preferences may vary between landscape planners and residents, which may result in differences between residents' demands and the actual design; whereas landscape planners might prefer rather natural areas with low accessibility and high species richness, residents may show a greater preference for formal parks (Hofmann, Westermann, Kowarik, \& Van der Meer, 2012).

In developing, planning or managing comprehensive urban green space networks it is also important to ensure that the local community is culturally connected to those places (Tzoulas \& James, 2010; Chen \& Jim, 2008). A socio-demographic profile of the residents, their primary uses (or non-uses) and perceptions of green areas are important factors to consider in landscape planning. People's habits when using parks and gardens are greatly influenced by the type of citizen (Sanesi \& Chiarello, 2006). The preferences also derive from basic physical, mental and security needs (Zhang, Chen, Sun, \& Bao, 2013). When taken into account, all those preferences help to design areas that better satisfy the users' needs and also potentially improve outreach to those not currently visiting the green spaces (Baur et al., 2013).

Resident and visitor perceptions and preferences towards urban green areas have been examined in a broad variety of contexts. Bjerke, Otsdahl, Thrane, and Strumse (2006) revealed that moderately dense vegetation received the highest ranking among those who participated in their questionnaire. Vegetation density was one of a number of environmental characteristics highly likely to contribute to the perceived appropriateness of urban parks for outdoor recreation (Bjerke et al., 2006). Middle-aged, well educated, wildlife interested, and "ecocentric" segments of the sample express a preference for more dense vegetation.

In Germany, a wide range of vegetation elements beyond planted street trees and wild roadside vegetation was met with a high approval (Weber, Kowarik, \& Säumel, 2014). In Cologne passers-by were asked on their primary use of roads and opinion about vegetation along roads; in Berlin the respondents were interviewed about roadside vegetation preferences and functions provided by that vegetation. Respondents were aware of various types of existing roadside vegetation and the ecosystem services provided. 
In Norway, respondents found enclosure, a calm atmosphere, shelter and good seating to be important elements in urban parks. (Nordh \& Otsby, 2013). 58 students in Oslo University College were asked to rank different park images according to their likelihood of choosing each place for resting and recovering after a long walk. Presence of "natural" elements received higher rankings, while lack of vegetation was associated with low ratings. Enclosure, calm atmosphere, shelter and good seating were identified as important elements in urban parks.

While wanting to be in nature is consistently reported as a reason to visit public green space, not enough is known about which components of the natural environment are particularly important (Irvine et al, 2010). 'A lot of grass', 'a lot of flowers/plants' and 'water features' are examples of attributes identified in the survey by Nordth \& Otsby (2013). Our aim is to use Choice Experiment based methodology as an innovative means of eliciting user preferences towards vegetation, which in turn may serve as predictors of square visitation and lead to a more comprehensive valuation of green infrastructure.

\section{Methods}

We interviewed users in both sections of the Convalecencia Square to assess their preferences and attitudes towards vegetation and their use of this public space. Data was gathered by means of in-person interviews (questionnaire available from authors upon request); we interviewed 150 visitors from January 30 to March 18, 2014. Authorization to conduct interviews was obtained from the university Institutional Review Board. Visits were divided between weekdays and weekends following a 9:00AM to 4:00PM schedule. We used two main models, a tripartite model (Maio \& Haddock, 2010) that considers cognitive, affective and behavioral components to explain attitudes towards green areas, and a choice experiment based model to identify key attributes of importance to town square users.

The tripartite model based survey contained Likert questions on cognitive components that included parking, governance issues, changes in temperature and shade due to the presence or absence of vegetation, and adding proposed descriptions of plants and trees at the square. Affective questions included feelings of well being, amusement and relaxation while visiting the square, the elicitation of memories while at the square, the impact on quality of life, and the perceived sense of beauty due to the presence of vegetation. Behavioral questions included respondents' preferred locations in terms of shade and temperature at the square, socializing at the square, the number of people accompanying visitors, square suitability for public activities, and observation of nature.

An adaptation to Choice Experiment (CE) methodology (Champ, Boyle, \& Brown, 2003), commonly used in Environmental Economics to elicit user valuation of non-market environmental attributes, was also used to assess user preferences towards existing and hypothetical gray/green infrastructure configurations in the Convalecencia Square. CEs have been used in a variety of contexts related to green infrastructure. Previous uses include examining the potential for development of ecotourism in rural communities (Chaminuka, Groeneveld, Selomane, \& Van Ierland, 2012), valuing tradeoffs in park development scenarios with a focus on biodiversity and recreational services (Juutinen et al., 2011), examining preferences for wood surface allocations in rural lands (Vecchiato \& Tempesta, 2013), and examining the preferences of urban dwellers for various attributes of urban forests with an emphasis on forest recreational services (Koo, Park, \& Youn, 2013). On the topic of urban area vegetation, both Juutinen et al. (2011) and Koo et al. (2013) report a preference for rich biodiversity in urban parks.

A traditional CE associates a particular dollar amount a respondent is willing to pay in exchange for a bundle of attributes. One would normally associate a particular dollar amount with an improvement in one or more attributes. The use of a two-picture scenario format, borrowed from CE methodology, allowed us to identify a user's preferred response to changes in attribute levels considered relevant in our study, in this case, vegetation and square infrastructure characteristics. The CE monetary component was substituted by an open-ended question to justify the selected scenario. The question had three main purposes: permitting an in-depth exploration of trends observed in Likert cognitive, affective and behavioral statements, allowing for the exploration of previously unidentified user perceptions and attitudes, and validating respondents' understanding of each scenario and associated terms such as green and gray. We believe the resulting innovative $\mathrm{CE}$ adaptation allowed us to account for environmental attribute preferences using a structured format while simultaneously identifying cultural values and meanings associated with the natural environment.

We created four different scenarios set in the recently renovated east side of the square, with variations in green area cover, shown in a two-picture format. We chose the east side because of its open and unused spaces, and its recent renovation, adding to the credibility lent to implementation of hypothetical configurations. Each scenario shows a particular variation in attributes, in a similar setting or background, ensuring respondents can focus on a particular attribute variation in each scenario. We had originally intended to include only three scenarios, but 
decided to incorporate a fourth (Scenario 2) to examine if scale would alter a respondent's perception of green spaces and vegetation. Alternative images were created using Adobe Photoshop CS5 software.

\section{Scenario 1 (see Figure 3)}

The original image is on the left side. This is the section of the square intended to be used for social events. The alternative hypothetical scenario is on the right. We replaced paving stones with the grass, added sitting areas with tables and a walkway through the grass.
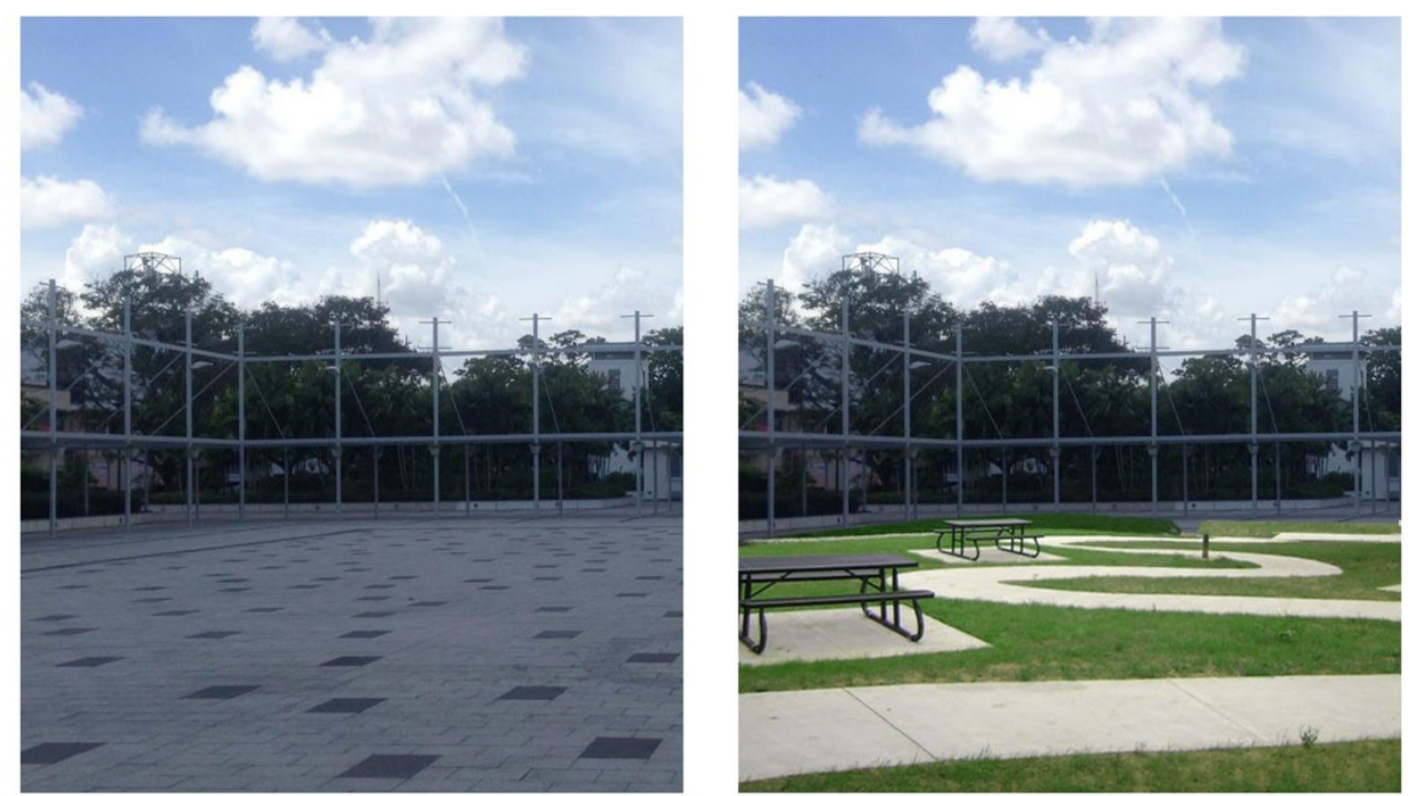

Figure 3. Scenario 1

\section{Scenario 2 (see Figure 4)}

The second scenario is the view of the square from above. The original present-day image is on the left. The western older section of the square has more vegetation while the eastern section contains additional pavement with trees, shrubs and other plants surrounding it. For the alternative hypothetical scenario, we have replaced the green areas in the western section of the square with pavement, replicating the pattern observed on the renovated east side.
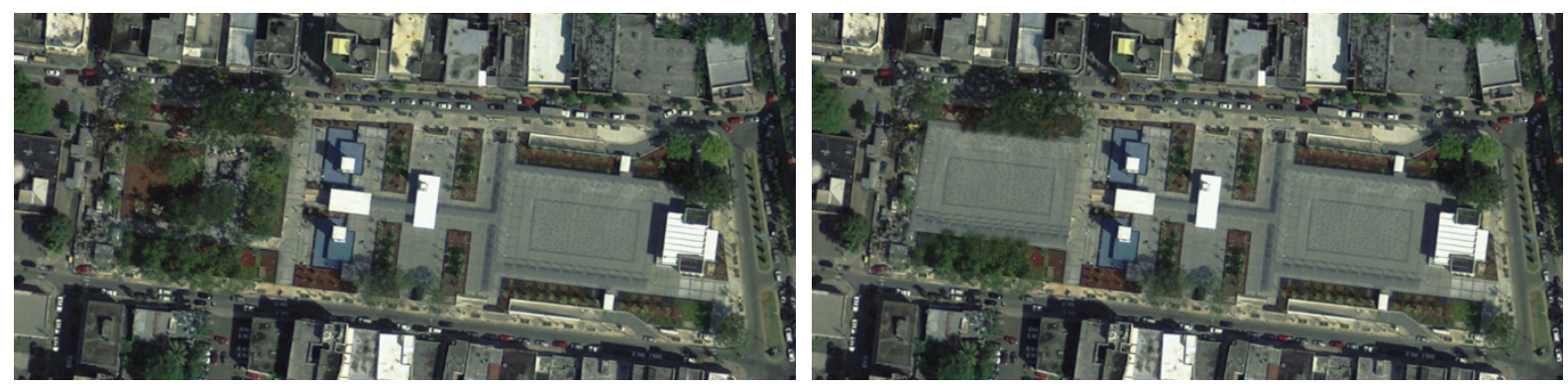

Figure 4. Scenario 2

\section{Scenario 3 (see Figure 5)}

For the third scenario we used a zoomed-in area of the renovated square shown in the first scenario, with a picture taken from a different angle. This time we have shown the complete replacement of paving stone with a hypothetical grass surface. This scenario presented extremes; one section of the square is fully paved, on the left, while the alternative hypothetical scenario is an area fully covered by grass, on the right. 

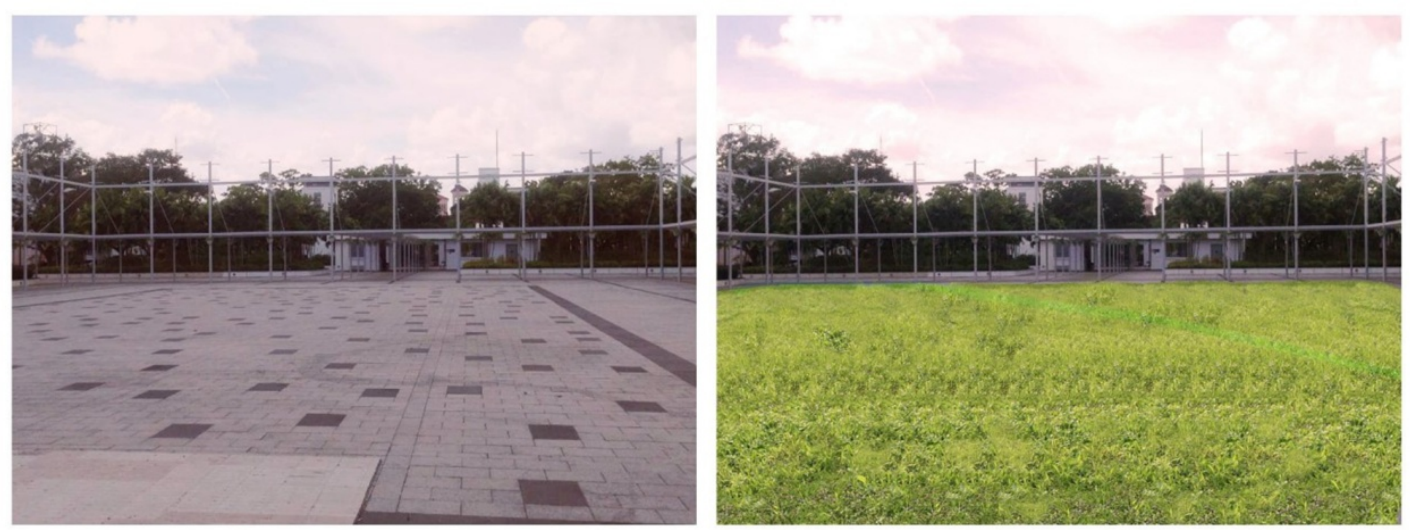

Figure 5. Scenario 3

\section{Scenario 4 (see Figure 6)}

The original photo in scenario four is identical to the one used for scenarios one and three. The reason for the use of the same picture in the three scenarios is to reduce the probability that a respondents' choice is due to reasons other than those intentionally changed in the picture, i.e. vegetation and some urban furnishings. In the hypothetical picture on the right we added three blossoming trees. The tree species, lagerstroemia speciosa, commonly known as Reina de las flores, was selected after consultation with US Forest Service personnel and a book on native trees in Puerto Rico (Schubert, 1979). The criteria for selection included the size of the tree, the extension of the roots, and aesthetic appeal. The selected tree species has been commonly planted in residential areas, parks, shopping centers and university campuses cross the island, making it a believable option in a local square setting. Numerous flowers would cover the tree's crown for about two months of the year.
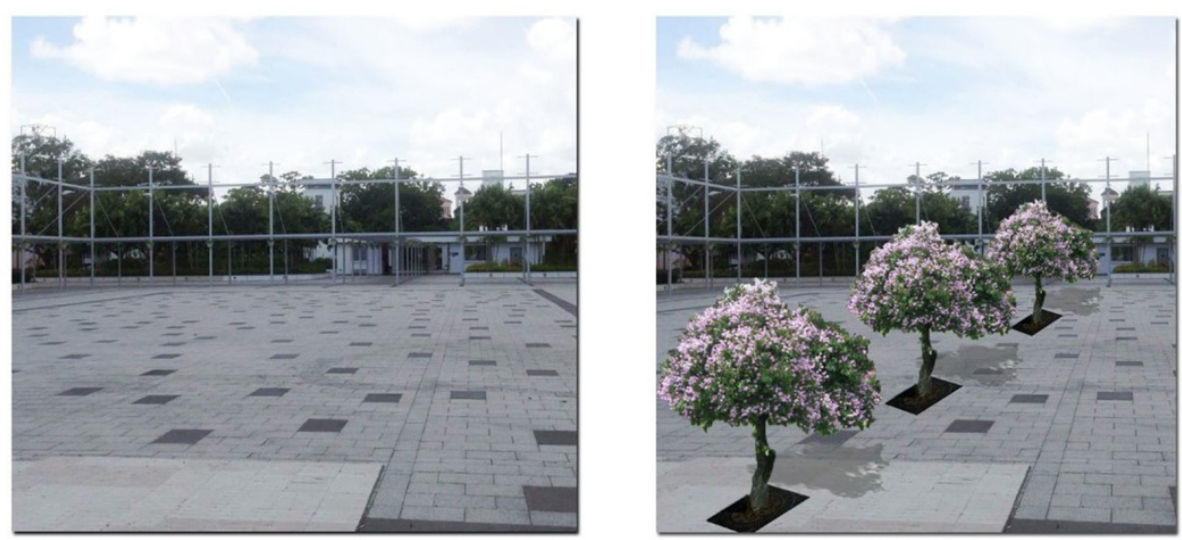

Figure 6. Scenario 4

\section{Findings}

\subsection{Visitor Profile}

The average survey respondent was a 48-year-old male with a high school degree and an annual average income of $\$ 13,000$. The sample was intentionally balanced between men and women ( $53 \%$ to $47 \%$ ), who were mostly Puerto Rican residents (97\%). The average interviewee visited the square with one or two other people.

$60 \%$ of respondents were interviewed in the older section, while the remaining $40 \%$ were intercepted in the rebuilt area. When asked which section of the square they prefer, more than half of respondents, or $52 \%$, preferred the rebuilt (east) section, while 35\% preferred the older (west) area. Only $4 \%$ indicated preferring both equally.

When respondents were asked to describe the activities they were conducting at the town square, $44 \%$ indicated they were resting, $37 \%$ were waiting for public transport, $21 \%$ were socializing, and $11 \%$ were conducting purchases in nearby stores. A smaller percentage of respondents indicated talking on their cellular phone $(9 \%)$, eating and drinking $(8 \%)$, and reading $(6 \%)$. 
Transport merits further exploration since nearly four in ten respondents described waiting for public transport as one of their main activities. It is not surprising that $34 \%$ reached the square walking, or that $14 \%$ used the train, given that there is a metro station adjacent to the town square. The square, as many others in Latin America and the Caribbean, serves as a public transport hub; $26 \%$ arrived by public bus, and 5\% used smaller private local buses. An unexpected result was that $20 \%$ used an automobile to access the square, given there are few adjacent ample parking areas. The remaining $1 \%$ of respondents used a motorcycle or a bicycle to access the town square.

\subsection{Cognitive, Affective and Behavioral Orientation}

An examination of cognitive, affective and behavioral Likert questions shows an overall positive orientation towards vegetation in the town square. A majority of respondents approved of its perceived benefits, reported a positive emotional connection, and agreed with behavior that valued green areas. When asked cognitive questions, there was agreement on the importance of vegetation in the general provision of ecosystem services. The majority of those interviewed believe they had selected the square location with more available shade and lower temperature. A large majority of visitors (97\%) agree that green areas are generally important, and a similar proportion (94\%) indicated that existing vegetation is key for the provision of shade in the area. Responses were also quite uniform when institutional cognitive questions were examined: more than $80 \%$ agreed that town square upkeep and maintenance is the responsibility of both the public sector and the community.

There was also general agreement in the evaluation of affective components; for most respondents, visiting the square generally elicited positive feelings. A majority of respondents indicated that they agreed with experiencing a feeling of relaxation, wellbeing, and amusement when they visit the square. More than $97 \%$ of respondents indicate that plants and trees contribute to the scenic beauty of the town square. Two negative affirmation questions were included to ensure the consistency of respondents' answers while examining affective components. When presented with the statements "I would like to see a Town Square with no trees" and "I would like to see a Town Square with no plants“, $97 \%$ disagreed with both statements.

The orientation of behavioral questions was not as definitive as in the other two categories. Although there was an overall positive orientation towards vegetation, results were not as clear when asked about socialization practices at the square. More than $80 \%$ of respondents agreed with the town square's suitability as a place to admire and observe nature. $94 \%$ look for shade when visiting the town square, while only $17 \%$ look for sunny places to sit or stand. When asked about socializing behaviors, $69 \%$ agreed with the statement on speaking to strangers when visiting the town square; this figure may seem high in particular cultural contexts. Other data pointing to social practices at the square was the level of agreement with statements on visitation with others (nearly half said they did not visit the Square alone) and on the square as an ideal public place for public gatherings, shows and activities ( $82 \%$ agreement). One possible confounding factor when examining social behavior is a visitors' opinion of security in public spaces such as a town square; it is possible a perceived lack of safety may diminish social activity and affect gregarious nature. The topic merits further exploration in subsequent research.

\subsection{Choice Experiment Based Scenario Preferences}

When presented with the four square gray/green area configurations previously described, participants were asked to choose between one of two photos per scenario representing different vegetation levels. For each selection made, respondents were asked to justify their choice. In all four scenarios, the majority of respondents consistently selected the photos with a higher proportion of green areas. There were, however, substantial differences in levels of agreement, ranging from $60 \%$ to $99 \%$. We will explore the possible sources of these variations in detail.

\section{Scenario 1 (Benches)}

There was an overwhelming preference for more vegetation in this scenario: $91 \%$ of respondents preferred the square shown on the right hand side, with the addition of grass and benches. The majority of respondents' answers point to the importance of vegetation when faced with the selection. Of those who selected the grayer scenario, only one person used the word "vegetation".

In this case, the greener scenario also included square benches. A large number of respondents (64) reported selecting this scenario not just because of the vegetation, but also because of the presence of benches. There were also references to intangible attributes. Ten others used the words "beautiful", and "looks better" to describe this scenario. Six respondents used the words "family environment" to describe the greener scenario with benches. Only two people justified this selection with exercise-related activities, mentioning "facilities for walking and running", and two others associated the greener scenario with "shade". 


\section{Scenario 2 (Birds Eye View)}

When presented with a "birds eye view" of the square, it was interesting to note a more balanced proportion in terms of respondent preferences. Even though $60 \%$ selected the greener scenario, the remaining $40 \%$ was the highest percentage of respondents who chose a less green scenario. Given that this scenario is the only one presented from a "birds eye view", we speculate that scale may have been a reason contributing to favoring the "grayer" scenario. One possible hypothesis could be that variations in scale may serve as determinants when presenting gray/green scenario choices to respondents. Further research should consider that participants are generally more familiar with ground views, and may need further clarification if bird's eye view images are used. To ascertain patterns are associated with scale and ensure the robustness of results, it may be appropriate to balance $\mathrm{CE}$ scenarios so an even number of bird's eye and ground views are presented.

Once again, the concept most frequently used to describe the greener scenario is vegetation, mentioned by 59 respondents. "Shade" was the second most frequently mentioned word (11), while "oxygen" was only mentioned twice. This scenario elicited more provision and regulation ecosystem service related responses than the first one. Also noteworthy was the response of seven participants pointing to aesthetics, indicating it was "beautiful" and that they "liked how it looks".

We found a statistically significant association between scenario 2 and gender. Even though a majority of men and women preferred the square with more vegetation, the one depicting the current state of the square, a higher proportion of women stated a preference for it (Pearson chi-square $\operatorname{Pr}=0.072$, Kendall's tau-b $=0.14$ ). When age was examined, even though both age groups, younger and older than 47 years old, prefer the current greener scenario, the proportion was higher for those over 47 . An increase in age was positively correlated to a greener square (Pearson chi-square $\operatorname{Pr}=0.04$, Kendall's tau-b $=0.16$ ).

\section{Scenario 3 (All Grassy Field)}

The all grassy field scenario was preferred by $76 \%$ of participants. Once again, vegetation was the most frequent justification for selecting the greener scenario, mentioned 57 times. Only three respondents mentioned air or oxygen, a tie to provision ecosystem services, as a reason for selection. Three respondents also mentioned beauty, a cultural ecosystem service, as a key criterion.

The responses used to justify the less green all-paved scenario are especially revealing. Seventeen participants indicated that a reason for choosing the all-paved scenario was that the grassy area looked abandoned, seemingly associating the grass area with a lack of care of green areas. A positive association was also made between pavement and cleanliness, as well as walking and running (seven respondents). Only two respondents mentioned the all-paved surface as a potential space for activities and shows.

When gender was considered, once again a larger proportion of women preferred the square with the all grassy field (Pearson Chi-square $\operatorname{Pr}=0.06$, Kendall's tau-b $=0.16$ ). . Even though a majority of men and women preferred greener scenarios, the proportion of women to men was significantly higher in this picture set and the previous one. There was also a statistically significant difference between the respondent's location in the square at the time when the survey was administered and a preference towards more grass; a much larger proportion of respondents in the new town square stated a preference for the all grassy field (Pearson chi-square Pr. $=0.07$, Kendall's tau- $b=0.15$ ).

Even though the majority still rejected the grayer scenario, it was not as definitive as in the other scenarios; $40 \%$ of respondents stated a preference for the fully paved square, which can also be interpreted as a rejection of an all green area. The occurrence of the notion of hygiene in the justifications for scenario selection is a reminder of the hygienic city imaginary described by Gandy (2004), among others.

\section{Scenario 4 (Flower Trees)}

An overwhelming majority, $99 \%$ of respondents, preferred the option with flower trees. Vegetation, particularly trees and flowers, was mentioned by 114 respondents as a reason for selecting the greener scenario. Scenario justifications included various aesthetics-related responses, associated with cultural ecosystem services, possibly due to the presence of flower trees. Beauty was mentioned by thirteen respondents (the highest frequency for this category across all scenarios). Only four respondents mentioned air/oxygen and shade, terms commonly associated with ecosystem service provision and regulation.

Recurring Themes

Aside from vegetation, which is the more obvious association that could be made when justifying the previous scenarios, there were four major underlying themes that were consistently found in respondents answers across all scenarios: aesthetics (62\%), ecosystem service provision and regulation (36\%), hygiene (23\%), and recreation (22\%). 
The strong link between aesthetics, trees and flowers was evident in the scenario selection process and in responses to affective questions. $97.5 \%$ agreed with the statement that trees and plants add beauty to the square, and disagreed with the notion of having a square without plants and trees. The overwhelming preference for trees, especially flower trees, can make green areas more attractive to potential users.

Aesthetics was, by a large margin, the most prevalent recurring theme and the most recognized ecosystem service by respondents. It is interesting to note that an intangible cultural service such as this one is more broadly recognized than other more perceptible provision and regulation services, such as carbon sequestration and oxygen production, or even temperature regulation.

Our findings regarding visitors' aesthetic preferences were consistent with a study conducted by Qiu, Lindberg, \& Nielsen (2013) in Helsingborg, Sweden, where visitors' preferences for green areas were shown to be guided by the immediate visual quality of the landscape, rather than by its recreational potential, and its immediate perception of beauty and serenity. The aesthetic quality of parks has also been identified as a determinant of visit frequency (Kazmierczak, 2013). That study confirmed the importance of a park's maintenance in attracting visitors. Flowers as a key aesthetic component were also studied in Sapporo, Japan (Todorova, Asakawa, \& Aikoh, 2004). Consistent with our findings, flowers were identified as the most preferred element beneath street trees (among choices of soil, grass, and hedge) and were also reported to attribute value beyond aesthetics to include psychological well-being.

Even though recognized in some way by $36 \%$ of respondents in the scenario justification process, ecosystem service provision and regulation were still not immediately recognized or perhaps valued by a large percentage of the population. Ecosystem service provision and regulation were only statistically correlated with the third scenario, the one showing the broadest green versus gray gap. Within the context of this urban square and our study, recognized provision and regulation services were generally limited to a narrow group of services, i.e., shade and temperature regulation. One cognitive question on the role of trees in providing shade confirmed this finding. The second most frequently identified provision/regulation service, oxygen production, was only mentioned by an even smaller number of respondents.

A survey conducted in Bilbao, Spain (Casado-Arzuaga, Madariaga, \& Onaindia, 2013) did show consistency with our findings. Without previous knowledge of ecosystem services, visitors were mostly able to perceive the most evident ones, mainly cultural services, but after being provided more information, they began to demand other services, including provisioning and regulating services. Lo \& Jim (2012) also point out that more complicated and subtle ecological services, such as habitats for wildlife and collective social benefits of urban green spaces, receive limited attention from the public due to inadequacy in environmental knowledge and awareness.

Nearly one in four respondents associated one or more of the scenarios with notions of hygiene. The proportion of green to gray seems to have an impact on several users' perceptions of cleanliness. When posed as an affective question, the notion of "no green" was overwhelmingly rejected by $97 \%$ of respondents. Scenario justification responses conversely revealed that some users perceived too much green as "dirty" or "unkempt", while associating extensions of pavement as clean. The hygiene concept was more prevalent in both the second and third scenarios, where respondents had to choose between mostly paved or green scenarios, even though the choices were presented at different scales.

Another possible reason for the importance of cleanliness to a large portion of readers is its perceived association to safety (Kemperman \& Timmermans, 2014). Even though the association was not explicitly stated in our study, the high crime rate in our study area could be a possible underlying factor that may partially account for the significant frequency of responses including cleanliness.

Only the first and second scenarios were significantly correlated with recreation. We believe the reason for this association was the presence of benches and sidewalks or larger paved areas. The recreation theme itself was significantly correlated with age (-0.20) and level of schooling $(0.22)$. The younger and more educated the respondent was, the higher the association with recreation. Square recreation is currently limited not only by infrastructure provision, but also by existing regulations and enforcement. One activity in particular, skateboarding, was only observed in the older section of the square; users informed interviewers the use was recently prohibited in the rebuilt section. Regulatory factors may thus be inhibiting certain types of recreation activities in the square.

\section{Policy Implications}

We hope that research results will inform current policy on public urban green space provision by means of documentation of user attitudes, preferences, and uses towards green infrastructure in densely populated urban areas where quality green spaces are increasingly scarce. The effectiveness of this framework lies in the simplicity 
and complementarity of its structured and unstructured components. The CE component allows users to visually state a preference for specific green area attributes in alternative scenarios, while the open-ended questions allow us to explore user attitudes, preferences and meanings. Reflecting on our findings, four areas are particularly relevant to policy: education in ecosystem services, the role of aesthetics in visitation, the prevalence of the hygienic city imaginary, and the role of gender in green area conservation.

1). Visitors need to be educated in the variety of ecosystem services provided by green areas, and environmental stewardship opportunities should be provided. Only less than a third of the scenario justifications examined pointed to recognition, although limited, of the regulating and provisioning ecosystem services urban squares provide. There is an awareness of the role of vegetation in producing shade and regulating temperature, but only to a small degree when compared to other recurring themes, such as aesthetics. Awareness would be a first step in the road to inclusion of ecosystem service valuation in green area developments and initiatives. Community environmental stewardship is another path to increase awareness of ecosystem services, with the added benefit of enhancing green infrastructure, and producing provisioning, regulating and cultural ecosystem services (Krasny, Russ, Tidball, \& Elmqvist, 2014).

2). Aesthetically pleasing green areas may serve as a powerful predictor for visitation, supposing a strong link between visitors stated preferences and visitation patterns. Scenario analysis shows that nearly all respondents preferred the presence of trees and flowers. If there is an intention of re-acquainting residents and visitors with green areas in the city and the services offered, some attention should be dedicated to aesthetic components, not only in the design stage, but also in the maintenance of existing areas. There are many green spaces in the city of San Juan that are not properly maintained, thus limiting user access and a broader provision of ecosystem services. Another key component determining visitation is the range of potential activities that can be conducted in the square. In our case, the majority of reported activities were passive in nature; thus, green infrastructure may play a more critical role attracting such uses than other recreational activities such as sports.

$3)$. Those visitors who have a stronger adhesion to visions of a hygienic city may be more sensitive to the extent of green area cover in an urban square. They may prefer a higher gray to green ratio than those who adhere to more ecologically aligned principles. Given the prevalence of notions of hygiene when urban green areas are considered, a strong education component may be an effective tool in providing an alternative, competing vision of the city: one where green areas are considered key in the provision of ecosystem services necessary for subsistence and healthy living. Such a vision may also gain prevalence with a more appropriate accounting of the true value of ecosystem services. Even though visitors may perceive them as contradictory, hygienic and green visions of the city may actually complement each other through the incorporation of appropriate design elements.

4). Urban green area conservation and development strategies may be more effective if gender differences are considered. Gender, not income or level of education, was significantly correlated to the scenario selection process Women seem to be drawn in larger proportions to greener squares. It may thus be appropriate to design and test the effectiveness of gender targeted green area conservation and management strategies. It is important to recognize gender-differentiated roles, skills and practices in the conservation and sustainable use of natural resources in its spatial and temporal dimensions (United Nations Environment Programme [UNEP], 2004). Strategies would deliberately address men and women separately, considering that women and men have different roles and needs, and there is a gender dimension to institutions at all levels of society.

In conclusion, with the exception of those expressing visions akin to those of the hygienic city imaginary, users show very strong affective outlooks towards green infrastructure, placing emphasis on aesthetic components, and exhibiting a limited identification of cognitive components such as the role of ecosystem services. Education on green area ecosystem services could help bridge the gap between affective and cognitive components. Furthermore, gender differences on green infrastructure configuration choices point to the idea of exploring gender-differentiated green area conservation and development strategies.

\section{Acknowledgments}

We would like to thank Carmen Concepción for reading and providing feedback on our manuscript, the reviewers for their valuable suggestions, and Laura Martí and Alondra Ocasio for their assistance in preparing all figures.

\section{References}

Andersson, E., Tengo, M., McPhearson, T., \& Kremer, P. (in press). Cultural ecosystem services as a gateway for improving urban sustainability. Ecosystem Service. http://dx.doi.org/10.1016/j.ecoser.2014.08.002i 
Balram, S., \& Dragićević, S. (2005). Attitudes toward urban green spaces: integrating questionnaire survey and collaborative GIS techniques to improve attitude measurements. Landscape and Urban Planning, 71, 147-162. http://dx.doi.org/10.1016/j.landurbplan.2004.02.007

Baur, J. W. R., Tynon, J. F., \& Gomez, E. (2013). Attitudes about urban nature parks: A case study of users and nonusers in Portland, Oregon. Landscape and Urban Planning, 117, 100-111. http://dx.doi.org/10.1016/j. landurbplan.2013.04.015

Besser, D. T., McLain, R., Cerveny, L., Biedenweg, K., \& Banis, D. (2014). Mapping landscape values: issues, challenges and lessons learned from field work on the Olympic Peninsula, Washington. Environmental Practice, 16(2), 138-150. http://dx.doi.org/10.1017/S1466046614000052

Bjerke, T., Ostdahl, T., Thrane, C., \& Strumse, E. (2006). Vegetation density of urban parks and perceived appropriateness for recreation. Urban Forestry \& Urban Greening, 5, 35-44. http://dx.doi.org/10.1016/j.ufug. 2006.01.006

Casado-Arzuaga, I., Madariaga, I., \& Onaindia, M. (2013). Perception, demand and user contribution to ecosystem services in the Bilbao Metropolitan Greenbelt. Journal of Environmental Management, 129, 33-43. http://dx.doi.org/10.1016/j.jenvman.2013.05.059

Chaminuka, P., Groeneveld, R. A., Selomane, A. O., \& Van Ierland, E. C. (2012). Tourist preferences for ecotourism in rural communities adjacent to Kruger National Park: A choice experiment approach. Tourism Management, 33, 168-176. http://dx.doi.org/10.1016/j.tourman.2011.02.016

Champ, P., Boyle, K., \& Brown, T. (Eds.) (2003). A Primer on Nonmarket Valuation. Dordrecht, Netherlands: Kluwer Academic Publishers. http://dx.doi.org/10.1007/978-94-007-0826-6

Chen, S. S., \& Jim, C. Y. (2008). The Urban Forest of Nanjing City: Key Characteristics and Management Assessment. In M. M. Carreiro, Y. Song, \& J. Wu (Eds), Ecology, Planning, and Management of Urban Forests (pp. 259-278). New York, NW: Springer.

Gandy, M. (2004). Rethinking urban metabolism: water, space and the modern city. City, 8(3), 371-387. http://dx.doi.org/10.1007/978-0-387-71425-7_16

Hofmann, M., Westermann, J.R., Kowarik, I., \& van der Meer, E. (2012). Perceptions of parks and urban derelict land by landscape planners and residents. Urban Space \& Urban Greening, 11, 303-312. http://dx.doi.org/10.1016/j.ufug.2012.04.001

Irvine, K., Fuller, R. A., Devine-Wright, P., Tratalos, J., Payne, S. R., Warren, P. H ... Gaston, K. J. (2010). Ecological and psychological value of urban green space. In Jenk, M. \& Jones, C. (Eds.), Dimensions of the Sustainable City, Future City 2. London, UK: Springer. http://dx.doi.org/10.1007/978-1-4020-8647-2_10

Jim, C. Y. (2008). Opportunities and alternatives for enhancing urban forests in compact cities in developing countries. In Ecology, Planning, and Management of Urban Forests (pp. 259-278). New York, NY: Springer. http://dx.doi.org/10.1007/978-0-387-71425-7_9

Juutinen, A., Mitani,Y., Mäntymaa, E., Yasushi, S., Siikamäki, P., \& Svento, R. (2011). Combining ecological and recreational aspects in national park management: A choice experiment application. Ecological Economics, 70, 1231-1239. http://dx.doi.org/10.1016/j.ecolecon.2011.02.006

Kazmierczak, A. (2013). The contribution of local parks to neighborhood social ties. Landscape and Urban Planning, 109, 31-44. http://dx.doi.org/10.1016/j.landurbplan.2012.05.007

Kemperman, A., \& Timmermans, H. (2014). Green spaces in the direct living environment and social contacts of the aging population. Landscape and Urban Planning, 129, 44-54. http://dx.doi.org/10.1016/j.landurbplan. 2014.05.003

Koo, J. C., Park, M. S., \& Youn, Y. C. (2013). Preferences of urban dwellers on urban forest recreational services in South Korea. Urban Forestry \& Urban Greening, 12, 200-210. http://dx.doi.org/10.1016/j.ufug.2013.02. 005

Krasny, M. E., Russ, A., Tidball, K. G., \& Elmqvist, T. (2014). Civic ecology practices: Participatory approaches to generating and measuring ecosystem services in cities. Ecosystem services, 7, 177-186. http://dx.doi.org/10.1016/j.ecoser.2013.11.002

Lo, A. Y. H., \& Jim, C. Y. (2012). Citizen attitude and expectation towards greenspace provision in compact urban milieu. Land Use Policy, 29, 577-586. http://dx.doi.org/10.1016/j.landusepol.2011.09.011 
Maio, G., \& Haddock, G. (2010). The Psychology of Attitudes and Attitude Change. London, UK: Sage Publications Ltd.

Millennium Ecosystem Assessment. (2005). Ecosystems and Human Well-being: Synthesis. Washington, DC: Island Press.

Nordh, H., \& Otsby, K. (2013). Pocket parks for people- a study of park design and use. Urban Forestry \& Urban Greening, 12, 12-17. http://dx.doi.org/10.1016/j.ufug.2012.11.003

Qiu, L., Lindberg, S., \& Nielsen A. B. (2013). Is biodiversity attractive?-On-site perception of recreational and biodiversity values in urban green space. Landscape and Urban Planning, 119, 136-146. http://dx.doi.org/10.1016/j.landurbplan.2013.07.007

Sanesi, G., \& Chiarello, F. (2006). Residents and urban green spaces: The case of Bari. Urban Forestry \& Urban Greening, 4, 125-134. http://dx.doi.org/10.1016/j.ufug.2005.12.001

Santiago, L., Verdejo-Ortiz, J., Santiago-Bartolomei, R., Meléndez, E., \& García-Montiel, D. (2014). Uneven access and underutilization of ecological amenities in urban parks of the Río Piedras Watershed. Ecology and Society, 19(1), 26. http://dx.doi.org/10.5751/ES-06180-190126

Schubert, T. (1979). Trees for urban use in Puerto Rico and the Virgin Islands. Gen. Tech. Rep. SO-27. New Orleans, LA: U.S. Dept of Agriculture, Forest Service, Southern Forest Experiment Station.

Todorova, A., Asakawa, S., \& Aikoh, T. (2004). Preferences for and attitudes towards street flowers and trees in Sapporo, Japan. Landscape and Urban Planning, 69, 403-416. http://dx.doi.org/10.1016/j.landurbplan. 2003.11.001

Towards gender mainstreaming in environmental policies. (2004). In United Nations Environment Programme (UNEP), Women and the environment. (Chapter VI). Retrieved from http://www.unep.org/PDF/Women/ ChapterSix.pdf

Tzoulas, K., \& James, P. (2010). Peoples' use of and concerns about green space networks: A case study of Birchwood, Warrington New Town, UK. Urban Forestry \& Urban Greening, 9, 121-128. http://dx.doi.org/ 10.1016/j.ufug.2009.12.001

Vecchiato, D., \& Tempesta, T. (2013). Valuing the benefits of an afforestation project in a peri-urban area with choice experiments. Forest Policy and Economics, 26, 111-120. http://dx.doi.org/10.1016/j.forpol.2012. 10.001

Weber, F., Kowarik, I., \& Säumel, I. (2014). A walk on the wild side: Perceptions of roadside vegetation beyond trees. Urban Forestry \& Urban Greening, 13, 205-212. http://dx.doi.org/10.1016/j.ufug.2013.10.010

Wright Wendel, H. E., Zarger, R. K., \& Mihelcic, J. R. (2012). Accessibility and usability: Green space preferences, perceptions, and barriers in a rapidly urbanizing city in Latin America. Landscape and Urban Planning, 107, 272-282. http://dx.doi.org/10.1016/j.landurbplan.2012.06.003

Zhang, H., Chen, B., Sun, Z., \& Bao, Z. (2013). Landscape perception and recreation needs in urban green space in Fuyang, Hangzhou, China. Urban Forestry \& Urban Greening, 12, 44-52. http://dx.doi.org/10.1016/j.ufug. 2012.11.001

\section{Copyrights}

Copyright for this article is retained by the author(s), with first publication rights granted to the journal.

This is an open-access article distributed under the terms and conditions of the Creative Commons Attribution license (http://creativecommons.org/licenses/by/3.0/). 